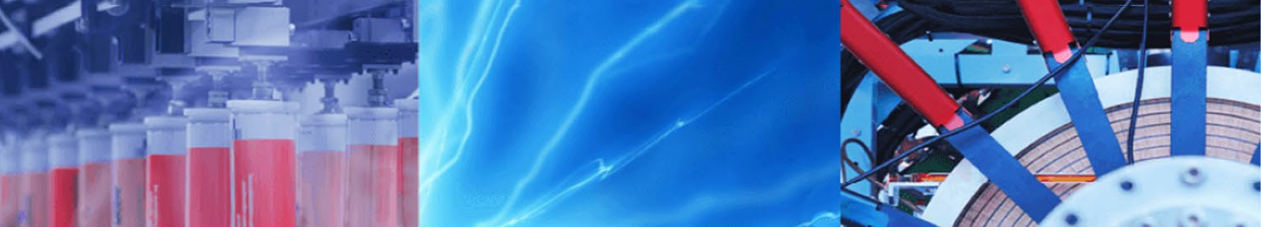

Research Article

\title{
Lead extraction as metallic phase from waste lead oxide-containing glass by redox reaction in hydrothermal treatment
}

\author{
Masanori Suzuki ${ }^{1}$ (D) Yuma Ukisu ${ }^{1} \cdot$ Norihiro Murayama $^{2}$
}

Received: 9 December 2020 / Accepted: 24 February 2021 / Published online: 4 March 2021

(C) The Author(s) 2021 OPEN

\begin{abstract}
A new low-energy and eco-friendly method for extracting lead from waste PbO-containing funnel glass is required. Conventional methods use either energy intensive smelting reduction at temperatures higher than $1273 \mathrm{~K}$ or involve phase separation of the glass, requiring an acid treatment to extract elemental $\mathrm{Pb}$ partitioned in one of the decomposed phases as $\mathrm{Pb}^{2+}$ ion. In this study, the mechanism of a unique phenomenon is investigated, involving spontaneous precipitation of metallic lead when $\mathrm{PbO}$-containing glass is subjected to a hydrothermal water environment in a stainless-steel container. The roles of the hydrothermal environment and container materials on the metallic lead precipitation were investigated. The synthesized PbO-containing glass was placed in a container made of stainless steel or pure iron and set in a sealed autoclave with water, which was held at $613 \mathrm{~K}$ to provide the hydrothermal conditions. As a result, metallic lead droplets precipitated either on the surface of the glass or the container, whereas an iron oxide $\left(\mathrm{Fe}_{3} \mathrm{O}_{4}\right)$ phase was detected on the surface of the container. Conversely, no metallic lead was observed when the glass and stainless-steel container were heated in dry air. The above results indicate that a hydrothermal environment is necessary for metallic lead precipitation because subcritical water or steam leaches $\mathrm{Pb}^{2+}$ from the glass. In addition, a redox reaction was suggested between the $\mathrm{Pb}^{2+}$ ions transported to the surface of the container and metallic iron in the container to explain metallic lead droplets precipitation.
\end{abstract}

Keywords Metallic lead $\cdot$ Waste funnel glass $\cdot$ Recycling $\cdot$ Hydrothermal treatment $\cdot$ Redox reaction

\section{Introduction}

Waste industrial glass, such as funnel glass from cathoderay-tubes (CRT) display devices, can contain up to 25 mass\% lead oxide $(\mathrm{PbO})$ to provide shielding from $\mathrm{X}$-rays $[1,2]$. Since CRT display manufacturing finished in 2015 , a large amount of waste funnel glass has been discharged around the world. There is a need to extract and recycle the lead from waste funnel glass to recover both the metal and the glass components.

In Japan, several methods have been proposed to extract lead from waste funnel glass $[3,4]$. One is to treat the glass in a smelting furnace to reduce the lead oxide to the metallic phase in a molten state with carbon monoxide gas. However, this process consumes a lot of energy because the reduction is normally conducted at temperatures higher than $1273 \mathrm{~K}$, even if a flux, such as sodium carbonate, is added to decrease the melt viscosity [5]. Another is to use phase separation phenomenon of borosilicate glass, whereby $\mathrm{B}_{2} \mathrm{O}_{3}$ is mixed with the waste glass in its molten state and phase separation occurs on annealing at $973 \mathrm{~K}$ to decompose the single glass phase into $\mathrm{SiO}_{2}$-rich and $\mathrm{B}_{2} \mathrm{O}_{3}$-rich glass phases [6-8]. The elemental $\mathrm{Pb}$ or other heavy metal elements selectively partition in

$\triangle$ Masanori Suzuki, suzuki@mat.eng.osaka-u.ac.jp| ${ }^{1}$ Division of Materials and Manufacturing Science, Graduate School of Engineering, Osaka University, 2-1 Yamada-oka, Suita, Osaka 565-0871, Japan. ${ }^{2}$ Faculty of Environmental and Urban Engineering Department of Chemical, Energy and Environmental Engineering, Kansai University, 3-3-35 Yamate-cho, Suita, Osaka 564-8680, Japan. 
the $\mathrm{B}_{2} \mathrm{O}_{3}$-rich glass phase. Finally, the phase-separated glass is washed by an acid solution to remove these elements from the $\mathrm{B}_{2} \mathrm{O}_{3}$-rich glass phase. The disadvantages of the above method are that it requires several steps to extract the lead, and an waste acid treatment is required. Therefore, a simpler and eco-friendly approach to extracting lead from waste funnel glass with a low energy consumption is required.

It has been reported that the phase separation of borosilicate glass is promoted under hydrothermal conditions with the use of saturated steam at $723 \mathrm{~K}$ [9], where a porous silica glass matrix is obtained as a result of phase decomposition into $\mathrm{SiO}_{2}$-rich and $\mathrm{B}_{2} \mathrm{O}_{3}$-rich glass phases with spontaneous removal of the latter soluble phase by water under the supercritical conditions. Because highlypressurized water has a much higher ion product value $\left(K_{\mathrm{W}}=\left[\mathrm{H}^{+}\right] \cdot\left[\mathrm{OH}^{-}\right]\right)$than $10^{-14}(\mathrm{~mol} / \mathrm{kg})^{2}$ than that of normal water, it can promote hydration of the vitreous structure in silicate glass to decrease the glass transition temperature [10] and leach out some oxide components [11]. By using the above features of highly-pressurized water, one of the authors have fabricated porous glass and ceramics from waste silicate slag and borosilicate glass [12]. Therefore, lead extraction from $\mathrm{PbO}$-containing borosilicate glass may be also possible by a single hydrothermal treatment. In this process, the glass is phase-separated under highpressure water or steam conditions, the elemental $\mathrm{Pb}$ preferentially partition into the $\mathrm{B}_{2} \mathrm{O}_{3}$-rich decomposed glass phase as $\mathrm{Pb}^{2+}$ ion, and are then spontaneously leached out by the high-pressure water.

However, our preliminary experiment on the hydrothermal treatment of $\mathrm{PbO}$-containing borosilicate glass, made from waste funnel glass and $\mathrm{a}_{2} \mathrm{O}_{3}$ additive, revealed that many micrometer-sized metallic lead particles deposited on the surfaces of the residual porous silica structure. The above hydrothermal treatment was performed under subcritical steam, where a piece of the synthesized PbO-containing borosilicate glass and a container made of stainless-steel mesh were placed apart from the water in a Hastelloy sealing autoclave and heated at $613 \mathrm{~K}$ to produce a highlypressurized steam atmosphere. Results of $\mathrm{X}$-ray diffraction, cross-sectional microstructure observations, and energydispersive X-ray (EDX) spectrometry of the residual silica glass after the hydrothermal treatment are shown in Fig. 1. Sharp diffraction peaks indicate the deposition of a metallic lead phase dispersed over the cross-section of porous silica matrix. This is a notable result because the elemental $\mathrm{Pb}$ initially existing as a lead oxide in the borosilicate glass was directly extracted as a reduced metallic lead phase by a single hydrothermal treatment of the glass. This approach may represent a simple, and eco-friendly method for extracting lead as a metal species from waste funnel glass with low energy consumption. However, the mechanism of reduction and precipitation of metallic lead during the hydrothermal treatment of the $\mathrm{PbO}$-containing borosilicate glass is not clear and requires further study.

Precipitation of reduced metal particles under a hydrothermal treatment has been previously reported in several papers: in one case, Adschiri et al. proposed a method to synthesize nanometer-sized metal particles by reduction of metallic acetate hydrate with hydrogen gas generated from formic acid under supercritical water conditions [13-15]. In another case, Jin et al. reported metallic copper deposition on a ceramic material when a metallic copper plate and ceramic material were subjected to a hydrothermal treatment under subcritical steam and a mixed nitrogen-oxygen gas atmosphere [16]. They proposed a mechanism for the metallic copper deposition, involving a reaction of the metallic copper plate with oxygen gas to form copper oxide $\left(\mathrm{Cu}_{2} \mathrm{O}\right)$ which reacts with subcritical steam, therefore elemental $\mathrm{Cu}$ to be dissolved in the subcritical steam as $\mathrm{Cu}^{+}$ion. Finally, the $\mathrm{Cu}^{+}$was partially reduced to metallic copper, which deposited on the ceramic material. However, the phenomenon occurring in our preliminary experiments cannot be explained by the above previously-proposed mechanisms because neither formic acid nor hydrogen gas were present as a reductant in this case.

Here, the mechanism by which lead metal precipitates from $\mathrm{PbO}$-containing borosilicate glass during hydrothermal treatments is examined under subcritical water and steam conditions. The subcritical water or steam environment likely leaches $\mathrm{Pb}^{2+}$ from the glass and a redox reaction occurs between $\mathrm{Pb}^{2+}$ ion in subcritical water and metallic species in the container to precipitate reduced lead metal particles. Hence, the effects of subcritical water or steam on the reduced lead metal precipitation are first investigated by comparing the resulting materials after a heat-treatment under dried air and hydrothermal treatments under subcritical steam and water. The effects of the reductant materials on metallic lead precipitation were also examined through the use of stainless steel, pure iron, and pure copper as container materials. In addition, lead extraction as metallic lead from the waste funnel glass by the hydrothermal treatment was attempted. On the basis of these experimental results and thermodynamic analysis of the subcritical water environment, a possible mechanism is proposed for metallic lead precipitation from waste funnel glass under the hydrothermal treatment.

\section{Materials and methods}

Two kinds of glass samples were treated in this study. Glass $A$, is a typical waste funnel glass, provided by Panasonic Eco Technology Center Co. Ltd., Hyogo, Japan. The average of 
(a) X-ray diffraction pattern

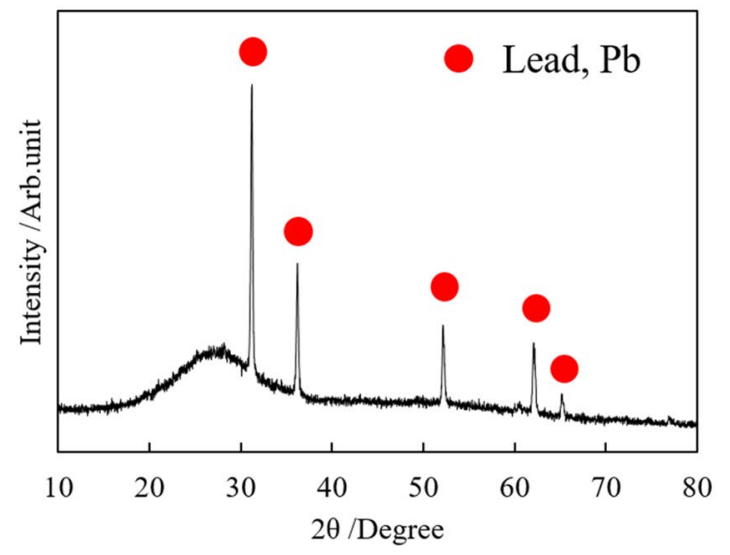

(b) Cross-sectional micrograph

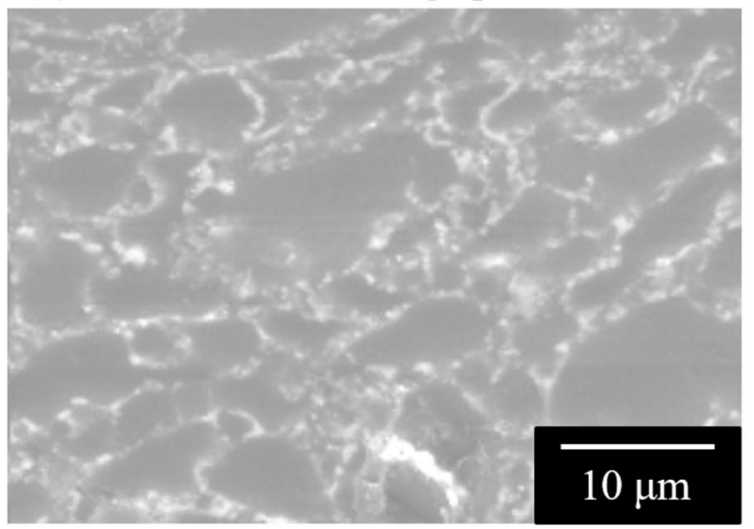

(c) EDX mapping of elemental $\mathrm{Pb}$

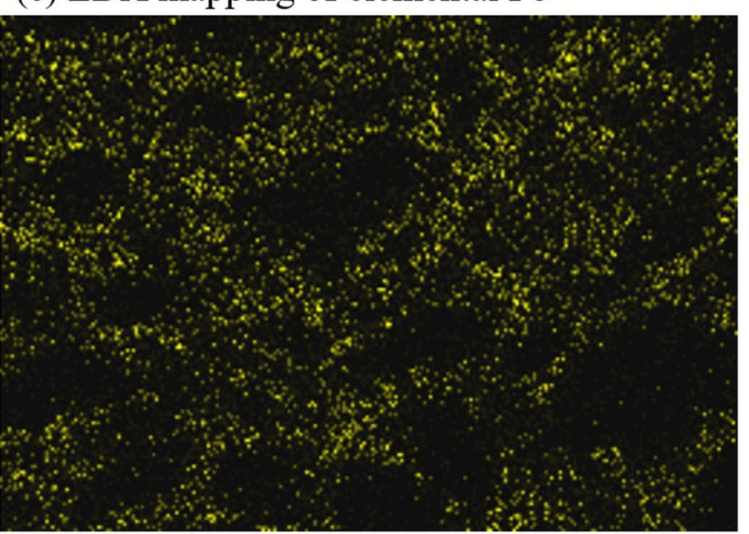

Fig. 1 Preliminary results of hydrothermal treatment of PbO-containing borosilicate glass: a X-ray diffraction pattern, $\mathbf{b}$ cross-sectional micrograph, and $\mathbf{c}$ EDX mapping of $\mathrm{Pb}$

the analyzed chemical composition of glass $A$ is summarized in Table 1. Glass $B$ was synthesized as follows: first, glass $A$ and 30 mass $\%$ of $\mathrm{B}_{2} \mathrm{O}_{3}$ (high-grade purity, provided by Kanto Chemical Co. Inc., Tokyo, Japan) were mixed in a powder state and the mixture was placed in a platinum-made crucible. The mixture in the crucible was completely melted at $1473 \mathrm{~K}$ for $1 \mathrm{~h}$, and then held at $1673 \mathrm{~K}$ for $1 \mathrm{~h}$ to homogenize the melt. Finally, the melt was poured on a thick Cu plate and quenched to a glassy state.

To perform the hydrothermal treatment, several pieces of the crushed glass sample (approximately $0.3 \mathrm{~g}$ in total), a container, and purified water were placed in a sealed autoclave made of Hastelloy-C alloy. A schematic diagram of the experimental setup for hydrothermal treatment, under either subcritical steam or water conditions, is illustrated in Fig. 2. The details of each treatment condition (dry, subcritical steam, and subcritical water) are summarized in Table 2 .
The heating temperature and holding time were set as $613 \mathrm{~K}$ and $48 \mathrm{~h}$ respectively. Because this target temperature is close to critical point of $\mathrm{H}_{2} \mathrm{O}$, subcritical steam or water can be produced. Under the dry heating condition, only the glass sample and container were sealed in the autoclave in a dry air atmosphere. For the subcritical steam conditions, the glass sample and the container were separated from the water by an Inconel-alloy rod, so that they were surrounded by $\mathrm{H}_{2} \mathrm{O}$ vapor generated under the hydrothermal treatment. The following Wagner empirical Eq. (1) was used to estimate the saturated vapor pressure of $\mathrm{H}_{2} \mathrm{O}$ [17], where $P[\mathrm{kPa}]$ is the saturated vapor pressure of $\mathrm{H}_{2} \mathrm{O}$ as a function of temperature, $T[\mathrm{~K}]$ is temperature, and $T_{\mathrm{C}}=647.3[\mathrm{~K}]$ and $P_{\mathrm{C}}=22,120[\mathrm{kPa}]$ are the temperature and pressure at critical point, respectively:
Table 1 Average chemical composition of waste funnel glass A (unit in mass\%)

\begin{tabular}{lllllll}
\hline $\mathrm{PbO}$ & $\mathrm{BaO}$ & $\mathrm{SrO}$ & $\mathrm{K}_{2} \mathrm{O}$ & $\mathrm{Na}_{2} \mathrm{O}$ & $\mathrm{Al}_{2} \mathrm{O}_{3}$ & $\mathrm{SiO}_{2}$ \\
\hline 23.2 & 0.8 & 0.8 & 8.5 & 6.7 & 0.7 & 59.3 \\
\hline
\end{tabular}


(a) Subcritical steam condition

(b) Subcritical water condition

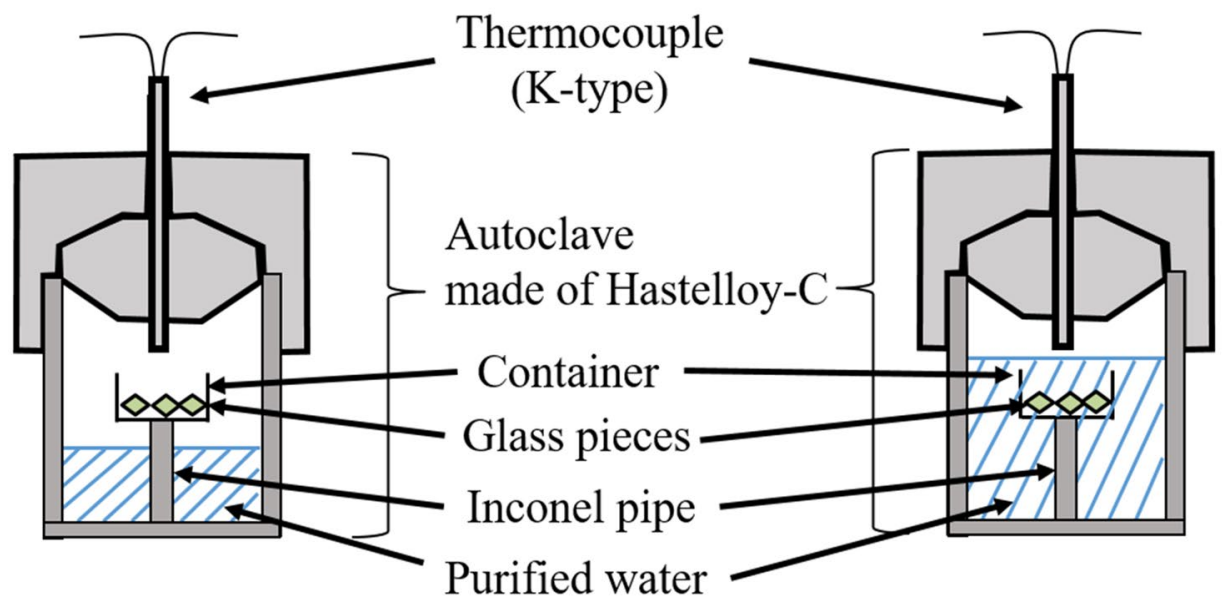

Fig. 2 Schematic diagram of experimental apparatus and setup for hydrothermal treatment

Table 2 Conditions of heating and hydrothermal treatments used in this study

\begin{tabular}{llll}
\hline Condition & Temperature /K & Holding time /hour & $\begin{array}{l}\text { Water } \\
\text { content / } \\
\text { gram }\end{array}$ \\
\hline Dry & 613 & 48 & 0 \\
S. Steam* & & & 2.0 \\
S. Water* & & & 7.0 \\
\hline
\end{tabular}

* S Subcritical

$\ln \frac{P}{P_{C}}=\frac{A \tau+B \tau^{1.5}+C \tau^{3}+D \tau^{6}}{1-\tau}, \tau=1-\frac{T}{T_{C}}$,

$A=-7.76451, B=1.45838, C=-2.7758, D=-1.23303$;

According to the Eq. (1), the saturated vapor pressure of $\mathrm{H}_{2} \mathrm{O}$ at $613 \mathrm{~K}$ is $14590 \mathrm{kPa}$. By applying the gas state equation and taking account of the inner volume of the autoclave $\left(11 \mathrm{~cm}^{3}\right)$, the minimum water content to achieve coexistence of vapor and liquid was estimated to be $0.567 \mathrm{~g}$. Under the subcritical water conditions, the glass sample and its container were both completely immersed in water. Consequently, the water content was determined for the subcritical steam and water condition, as listed in Table 2.

A stainless-steel wire net (60 mesh, $0.1 \mathrm{~mm}$ wire diameter), iron sheet $(0.1 \mathrm{~mm}$ thick $)$ and copper sheet $(0.1 \mathrm{~mm}$ thick), which were provided by Nilaco Corp., Tokyo, Japan, for use as materials for the container, which had a size of $6 \mathrm{~mm}$ (width) $\times 7 \mathrm{~mm}$ (depth) $\times 4 \mathrm{~mm}$ (height) to hold several pieces of the crushed glass sample.
After the hydrothermal or dry heat treatment, the resulting glass sample and its container were analyzed as follows: first, X-ray diffraction (XRD) analysis was performed on a Rigaku SmartLab SE (Rigaku Corp., Tokyo, Japan) with CuK $\alpha$ radiation, to detect the reduced lead metal and any other crystalline precipitates. Second, the surface microstructures were observed by a JEOL JSM5600 scanning electron microscope (JEOL Ltd., Tokyo, Japan) operating at an accelerating voltage of $15 \mathrm{kV}$ and the elemental distribution in the observed area was examined by an energy dispersive X-ray spectroscopy (EDX). Third, the average $\mathrm{Pb}$ content of the resulting glass sample was analyzed by a Rigaku Supermini 200 wavelength dispersive fluorescent X-ray (XRF) spectrometer (Rigaku Corp., Tokyo, Japan). Those samples without metallic lead precipitates were mixed with $\mathrm{Li}_{2} \mathrm{~B}_{4} \mathrm{O}_{7}$ in the molten state to produce glass beads for the above XRF analysis. In addition, the contents of elemental $\mathrm{Pb}$ and Fe dissolved in the condensed water of the autoclave were analyzed by inductively coupled plasma (ICP) spectroscopy analysis.

\section{Results}

\subsection{Effect of subcritical water environment on reduced lead metal precipitation}

In this section, the synthesized $\mathrm{PbO}$-containing borosilicate glass $B$ and the stainless-steel mesh container were subjected to either a heat treatment under dried air, or the hydrothermal treatments under subcritical steam and water, at $613 \mathrm{~K}$, as listed in Table 2 . In addition, the hydrothermal treatment at $523 \mathrm{~K}$ under subcritical water was 
also performed to investigate the effect of holding temperature on the metallic lead precipitation. Because ion product value $\left(K_{\mathrm{w}}\right)$ shows maximum at $523 \mathrm{~K}$ under saturated vapor pressure of $\mathrm{H}_{2} \mathrm{O}$, the reaction between $\mathrm{H}_{2} \mathrm{O}$ and lead oxide in the glass to extract lead as $\mathrm{Pb}^{2+}$ ion into the subcritical water was expected to be most accelerated.

Figure 3 shows the typical appearances of the glass samples after each treatment. Following dry heating (Fig. 3a), the resulting glass maintained its original transparent green appearance and no obvious changes were observed. However, for samples subjected to the hydrothermal treatment under subcritical steam (Fig. 3b), the resulting glass pieces became fragile, and expanded from their initial size. Additionally, the color of the glass changed to white or partially black. The glass pieces treated under subcritical water (Fig. 3c] had an even blacker appearance than those treated under subcritical steam. The fragility and the expansion of the glass samples is attributed to phase separation phenomena and subsequent formation of a porous structure under the hydrothermal treatment as reported by Sigoli et al. [9].

The XRD patterns of each treated glass sample are shown in Fig. 4. The heat-treated sample under dried air and the hydrothermally treated sample under subcritical steam maintained their glassy state, whereas the hydrothermally treated sample under subcritical water featured metallic lead precipitation. Although metallic lead was not detected in the sample hydrothermally treated under subcritical steam, the metallic lead precipitates might be locally dispersed in the microstructure.

Figures 5 and 6 show surface micrographs of the samples treated under subcritical steam and water, and the results of the EDX plane and point analyses of the corresponding observed areas. For the sample hydrothermally treated under subcritical steam (Fig. 5), a porous structure with pores several micrometers in diameter was observed and a small deposit was detected. The EDX point analysis indicated that the deposit had a high Pb content, which is

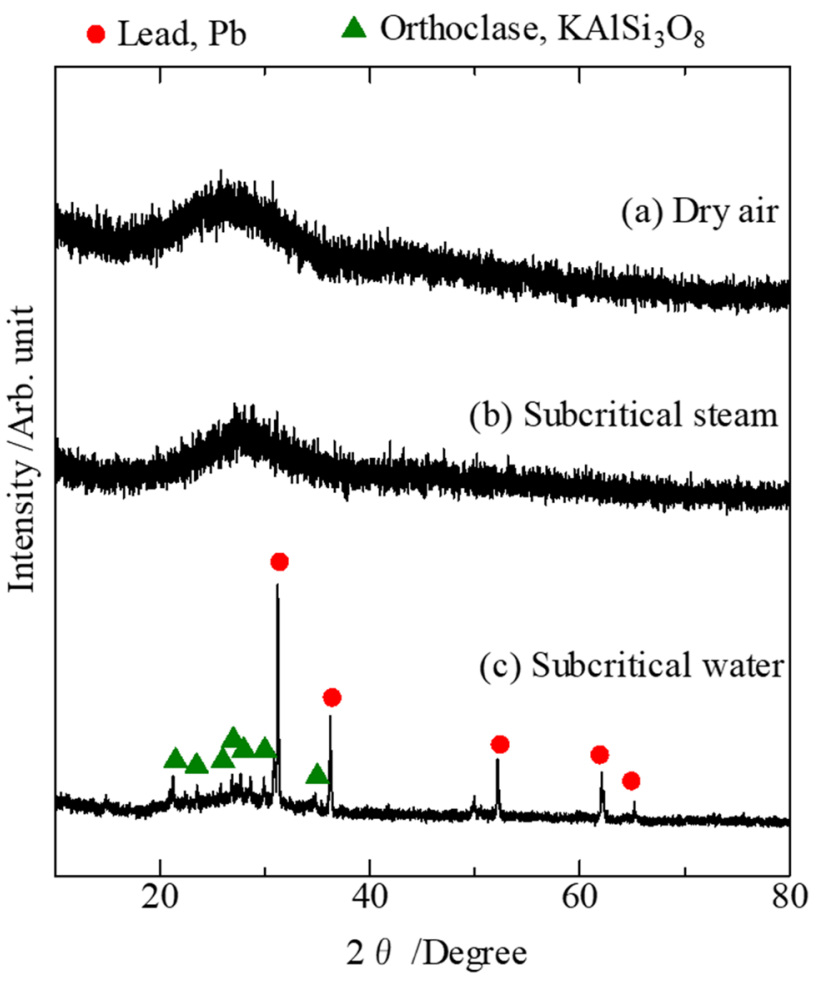

Fig. 4 X-ray diffraction patterns of glass sample B after heated at $613 \mathrm{~K}$ for $48 \mathrm{~h}$ in a stainless-steel container: (a) dry air, (b) subcritical steam, and (c) subcritical water

attributed to metallic lead. For the sample hydrothermally treated under subcritical water (Fig. 6), similar deposits of reduced lead metal were observed in the porous silica microstructure.

In contrast, the result of hydrothermal treatment at $523 \mathrm{~K}$ under subcritical water did not show metallic lead precipitation, as presented below. The glass sample changed its appearance to opaque-colored, indicating the crystallization of the glass (Fig. 7a). The XRD pattern of the glass sample is shown in Fig. 7b, where crystalline phases (a) Dry air

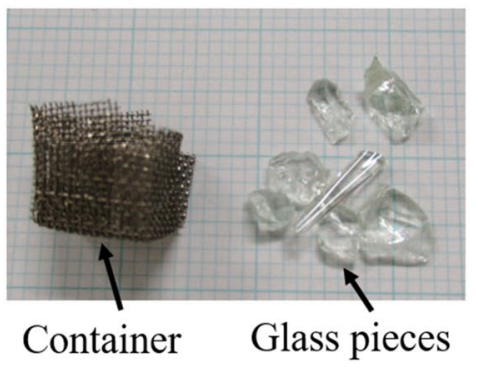

(b) Subcritical steam

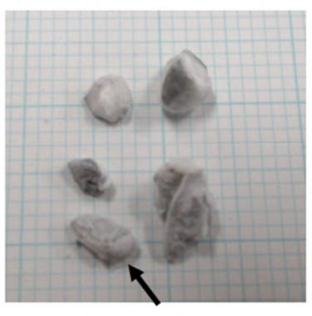

Glass pieces (c) Subcritical water

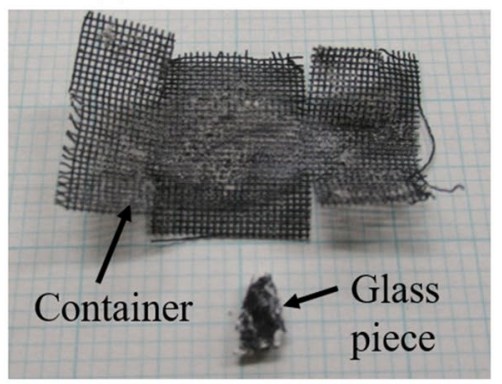

Fig. 3 Appearances of glass pieces after heating at $613 \mathrm{~K}$ for $48 \mathrm{~h}$ in a stainless-steel container: $\mathbf{a}$ dry air, $\mathbf{b}$ subcritical steam, and $\mathbf{c}$ subcritical water 
(a) Surface micrograph

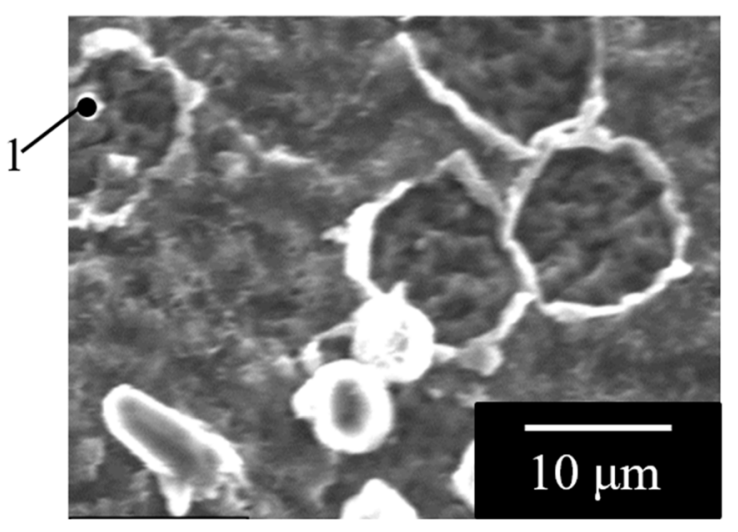

(b) EDX mapping of elemental $\mathrm{Pb}$

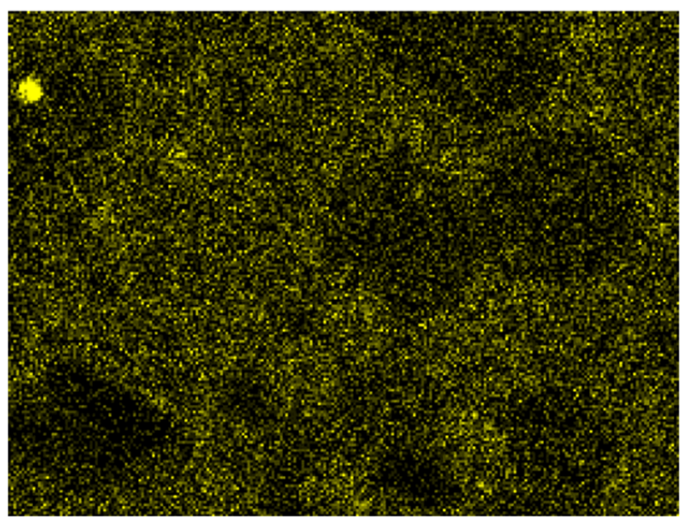

(c) Analyzed composition of marked point in (a)

\begin{tabular}{ccccc}
\hline \multicolumn{5}{c}{ Composition [at\%] } \\
No. & $\mathrm{Pb}$ & $\mathrm{K}$ & $\mathrm{Ca}$ & $\mathrm{Si}$ \\
\hline 1 & 78.8 & 1.5 & 2.2 & 17.5 \\
\hline
\end{tabular}

Fig. 5 a Surface micrograph, $\mathbf{b}$ EDX mapping of elemental $\mathrm{Pb}$, and $\mathbf{c}$ analyzed composition of marked point in (a) of glass $\mathrm{B}$, after subcritical steam hydrothermal treatment in a stainless-steel container at $613 \mathrm{~K}$

(a) Surface micrograph

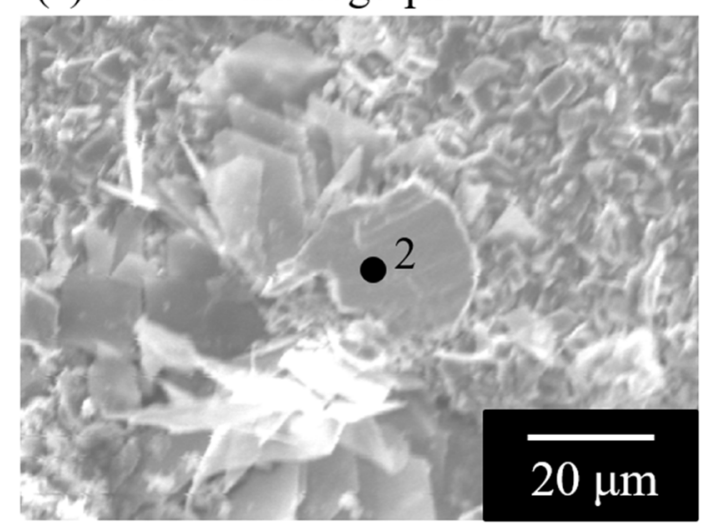

(b) EDX mapping of elemental $\mathrm{Pb}$

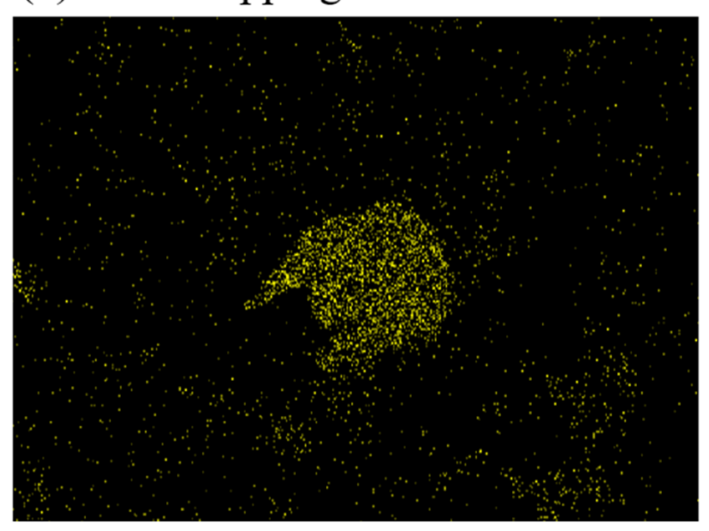

(c) Analyzed composition of marked point in (a)

\begin{tabular}{ccccc}
\hline \multicolumn{5}{c}{ Composition [at\%] } \\
No. & $\mathrm{Pb}$ & $\mathrm{K}$ & $\mathrm{Ca}$ & $\mathrm{Si}$ \\
\hline 2 & 85.9 & 1.8 & 4.8 & 7.5 \\
\hline
\end{tabular}

Fig. 6 a Surface micrograph, b EDX mapping of elemental Pb, and $\mathbf{c}$ analyzed composition of point marked in (a) of glass B, after subcritical water hydrothermal treatment in a stainless-steel container at $613 \mathrm{~K}$ 
(a) Sample appearance

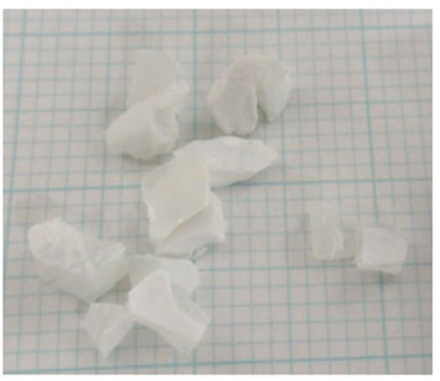

(b) X-ray diffraction pattern

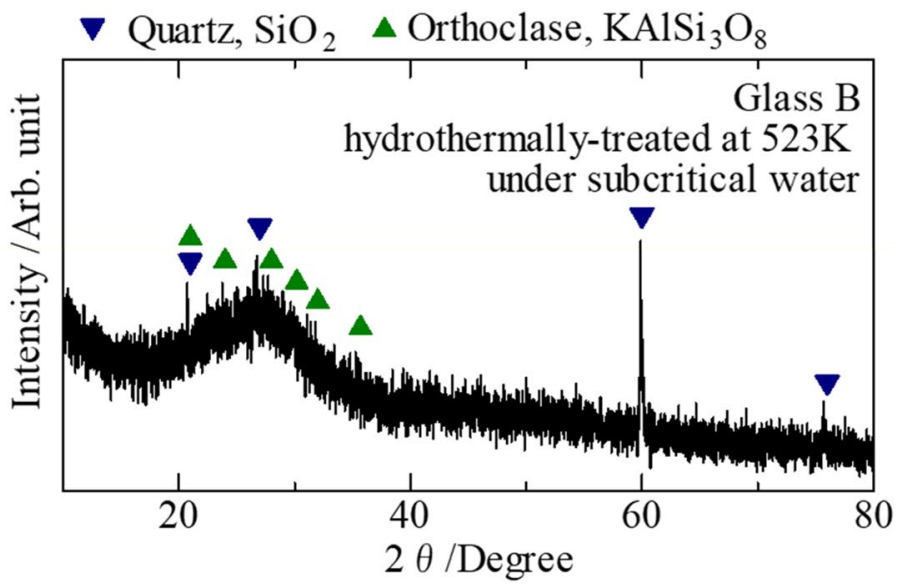

Fig. 7 a Sample appearance and $\mathbf{b}$ X-ray diffraction pattern of glass B after subcritical water hydrothermal treatment in a stainless-steel container at $523 \mathrm{~K}$ for $48 \mathrm{~h}$

Table 3 Analyzed $\mathrm{Pb}$ content in the condensed water after hydrothermal treatment of glass $B$ with a stainless-steel container ( $\mathrm{S}$. means Subcritical)

\begin{tabular}{llll}
\hline Condition & Temperature $/ \mathrm{K}$ & Container material & $\begin{array}{l}\mathrm{Pb} \\
\text { content / } \\
\mathrm{mg} \mathrm{L}^{-1}\end{array}$ \\
\hline S. Steam & 613 & Stainless steel & 13.8 \\
S. Water & 613 & & 59.5 \\
S. Water & 523 & & 10.1 \\
\hline
\end{tabular}

of $\mathrm{SiO}_{2}$ (quartz) and $\mathrm{KAISi}_{3} \mathrm{O}_{8}$ were detected but metallic lead was not found. Any metallic lead deposits were not found in the observed area of surface microstructure of the glass after the hydrothermal treatment at $523 \mathrm{~K}$.

Thus, in the present experimental conditions, metallic lead precipitates were observed only when the glass was hydrothermally treated at $613 \mathrm{~K}$ under subcritical steam or water.

The results of ICP chemical analysis showed a certain $\mathrm{Pb}$ content in the condensed water after the hydrothermal treatment (Table 3). Hence, elemental Pb dissolved in the condensed water, owing to leaching from the glass sample during the hydrothermal treatment. Furthermore, the condensed water used in the subcritical water condition had a higher $\mathrm{Pb}$ content than that used for the subcritical steam at $613 \mathrm{~K}$. However, the $\mathrm{Pb}$ content in the condensed water after the hydrothermal treatment at $523 \mathrm{~K}$ was obviously lower than that after the hydrothermal treatment at $613 \mathrm{~K}$. This indicates that the leaching of $\mathrm{Pb}^{2+}$ ion out of the glass to the subcritical water was promoted at $613 \mathrm{~K}$ rather than $523 \mathrm{~K}$, which may result in the possibility of metallic lead precipitation.
In contrast, elemental Fe was not detected in the condensed water after hydrothermal treatments.

\subsection{Effect of container material on lead metal precipitation under hydrothermal treatment}

The hydrothermal treatments of the PbO-containing borosilicate glass $B$ were conducted at $613 \mathrm{~K}$ under either subcritical steam or water conditions and with several kinds of container materials.

The results for the iron container subjected to the subcritical steam hydrothermal treatment, including the appearances of the glass sample and container and the XRD patterns of these samples are shown in Fig. 8. The glass sample became fragile and black in appearance after the hydrothermal treatment. The iron container lost its original metallic luster and changed to black. The XRD pattern of the resulting glass sample clearly showed metallic lead precipitation and the inner and outer surfaces of the container also both exhibited metallic lead and iron oxide (magnetite, $\mathrm{Fe}_{3} \mathrm{O}_{4}$ ) phases.

Figure 9a shows the sample appearances after the water hydrothermal treatment. Similar to the subcritical steam conditions, the glass sample became fragile, expanded, and grey in appearance. The iron container became black. XRD patterns of the glass sample and the container (inner and outer surfaces) (Fig. 9b) included crystalline phases of $\mathrm{SiO}_{2}$ (quartz), $\mathrm{KAISi}_{3} \mathrm{O}_{8}$ in the glass sample, and metallic lead and $\mathrm{Fe}_{3} \mathrm{O}_{4}$ (magnetite) were detected in both the inner and outer surfaces of the container. Thus, metallic lead precipitated on the iron container when $\mathrm{PbO}$-containing borosilicate glass $B$ was hydrothermally treated under both subcritical steam and water conditions. 
Fig. 8 a Appearance and $\mathbf{b}$ $X$-ray diffraction patterns of glass sample and iron container subjected to subcritical steam hydrothermal treatment at $613 \mathrm{~K}$ for $48 \mathrm{~h}$ (a) Sample appearance

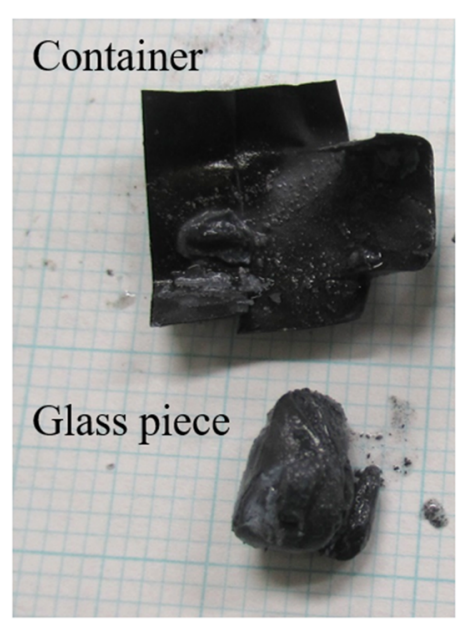

(b) X-ray diffraction pattern

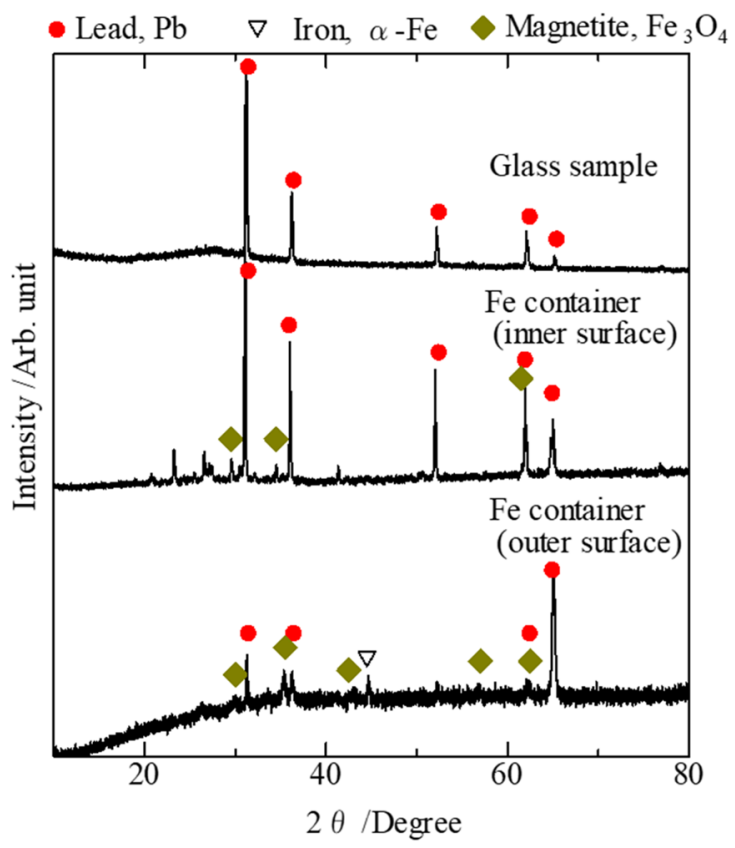

(a) Sample appearance

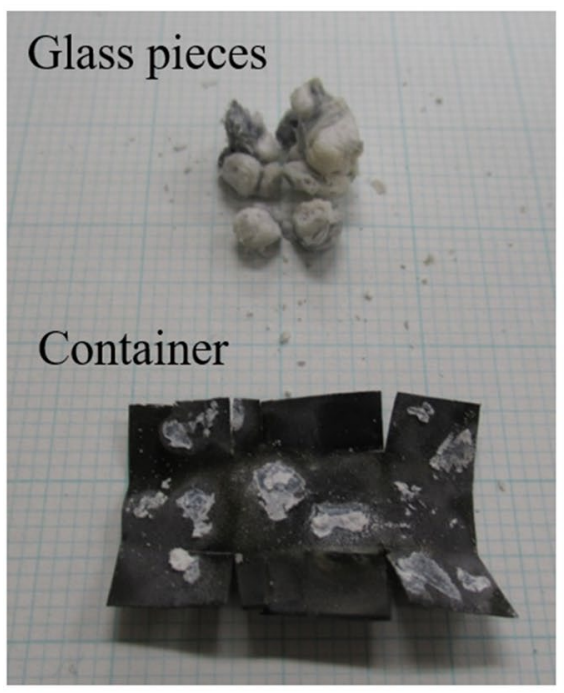

(b) X-ray diffraction pattern

- Lead, $\mathrm{Pb} \quad \boldsymbol{\nabla}$ Iron, $\alpha-\mathrm{Fe} \quad \boldsymbol{\nabla}$ Quartz, $\mathrm{SiO}_{2}$

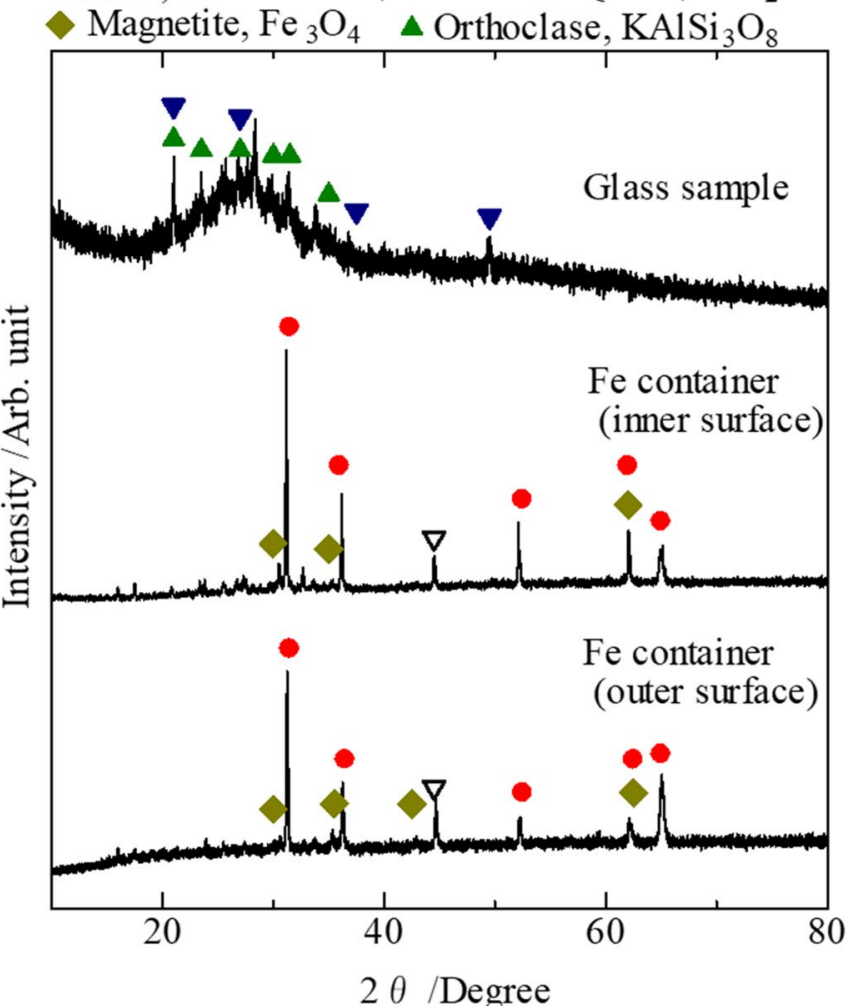

Fig. 9 a Appearance and $\mathbf{b}$ X-ray diffraction patterns of glass sample and iron container subjected to subcritical water hydrothermal treatment at $613 \mathrm{~K}$ for $48 \mathrm{~h}$ 
Figure 10 shows a surface micrograph and EDX mapping results of the iron container after the hydrothermal treatment of Glass B under subcritical water condition. Many spherical deposits of several tens micrometer in diameter were observed. The EDX maps clearly indicated that elemental $\mathrm{Pb}$ was distributed in these deposits, whereas elemental $\mathrm{Fe}$ and $\mathrm{O}$ were both distributed in gaps between the deposits. This result suggests that metallic lead precipitates and iron oxide phase were present at the surface of the iron container, which is consistent with the XRD result.

The results for the copper container were as follows. Because copper is more difficult to oxidize than lead, no reduction or precipitation of metallic lead was expected. The appearances of the glass sample and the container after the subcritical water hydrothermal treatment are shown in Fig. 11a. The glass sample became fragile, expanded, and white in appearance. The copper container did not lose its metallic luster even after the hydrothermal treatment. Figure $11 \mathrm{~b}$ shows XRD patterns of the glass sample and container after the hydrothermal treatment, indicating that several kinds of crystalline phases other than metallic lead were detected in the glass sample, whereas only metallic copper was detected in the container.

Table 4 summarizes the results of the ICP chemical analysis of the elemental $\mathrm{Pb}$ contents in the condensed water after the hydrothermal treatments with iron or copper containers. The condensed water from the iron container had a much greater $\mathrm{Pb}$ content than that from the copper container. Therefore, the subcritical water environment and presence of the container material promoted leaching of $\mathrm{Pb}^{2+}$ from the glass. The container material likely controlled the $\mathrm{pH}$ of the subcritical water during the hydrothermal treatment, as will be discussed later.

In summary, the iron container promoted metallic lead precipitation whereas the copper container suppressed the process.
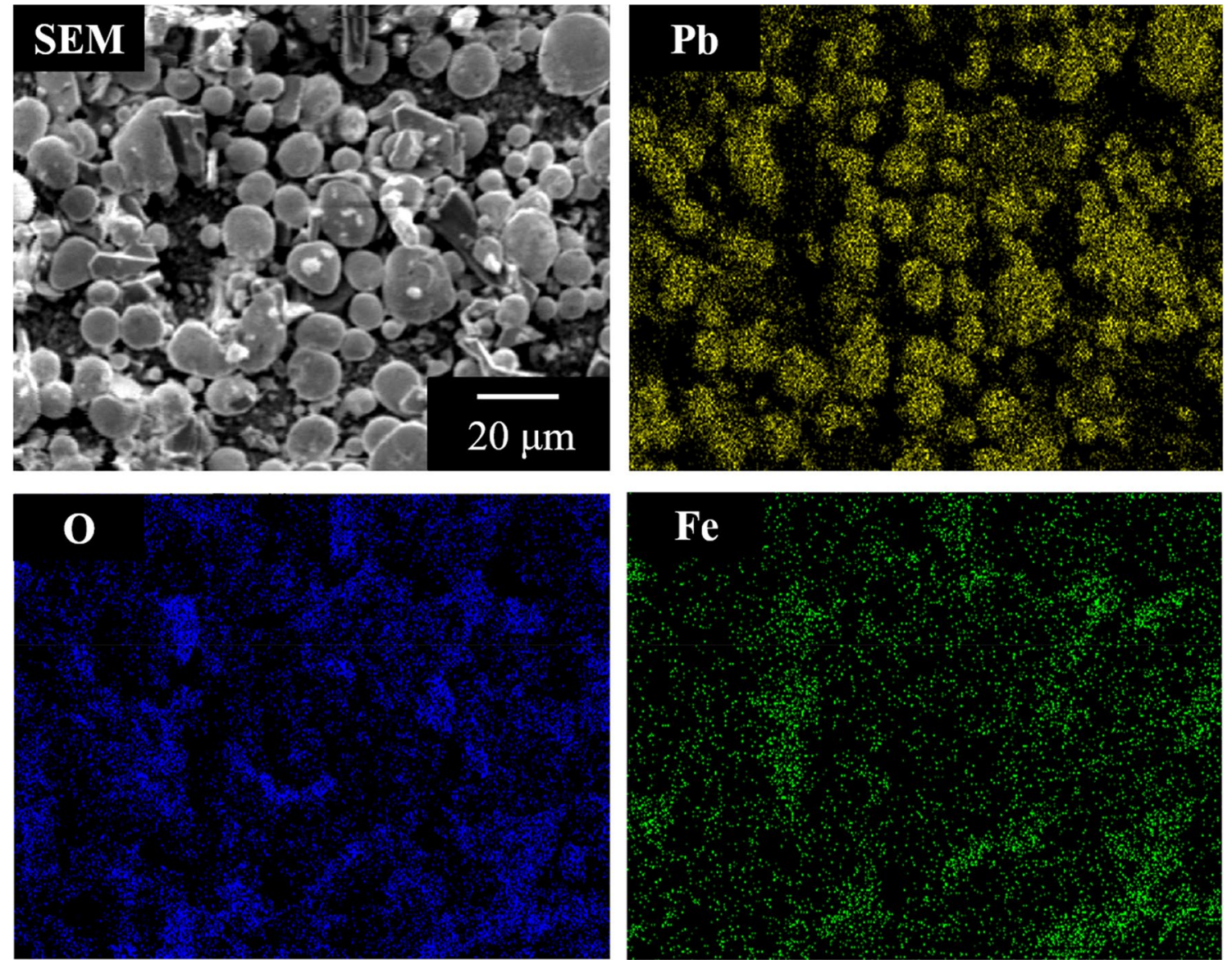

Fig. 10 Surface micrograph and EDX mapping results of iron container subjected to subcritical water hydrothermal treatment with glass $\mathrm{B}$ at $613 \mathrm{~K}$ for $48 \mathrm{~h}$ 
(a) Sample appearance

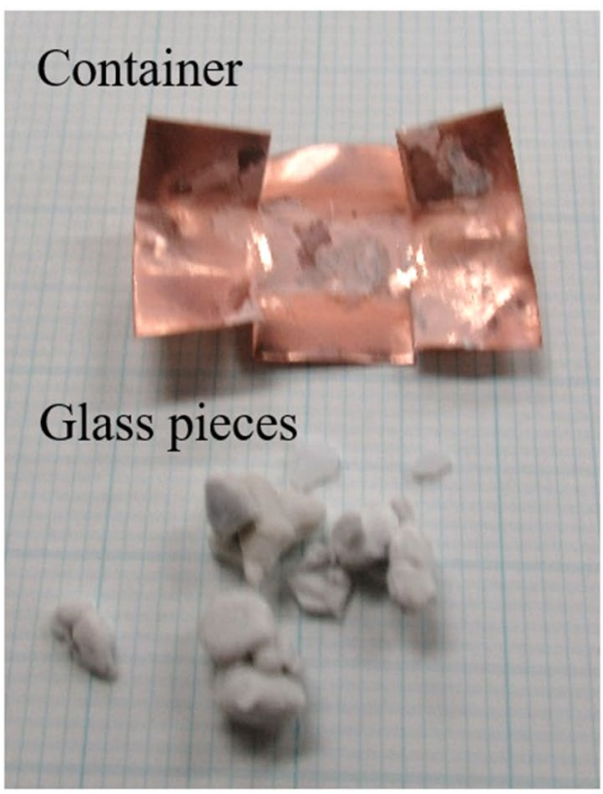

(b) X-ray diffraction pattern

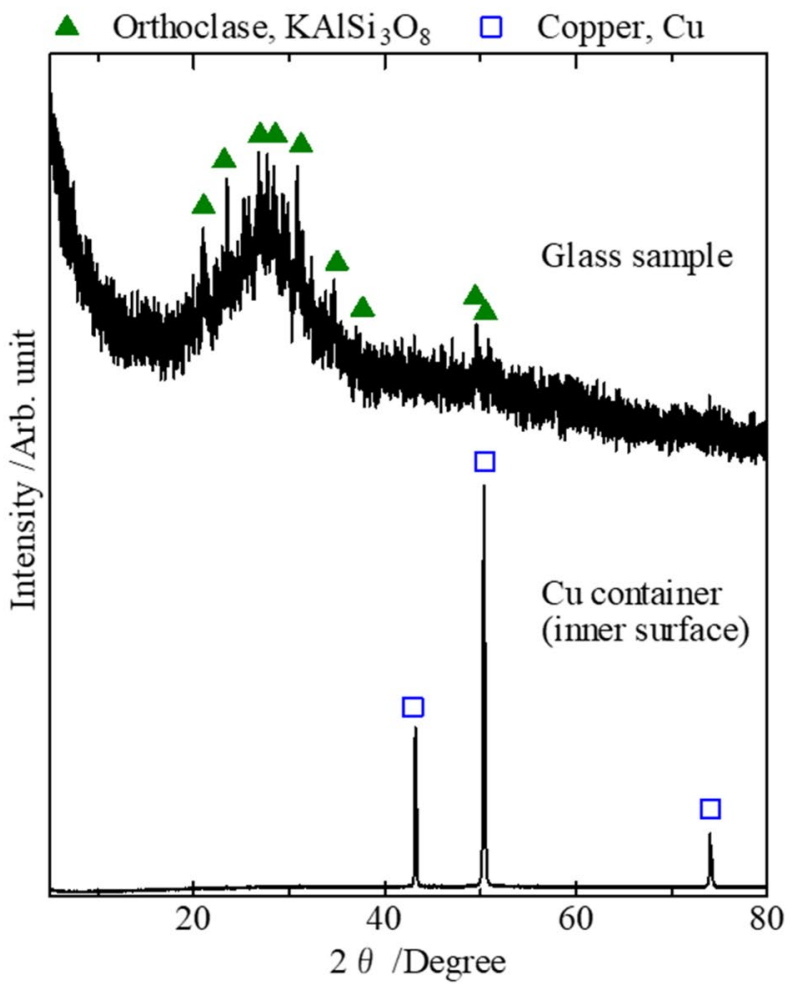

Fig. 11 a Appearance and $\mathbf{b}$ X-ray diffraction patterns of glass sample and copper container subjected to subcritical water hydrothermal treatment at $613 \mathrm{~K}$ for $48 \mathrm{~h}$

Table 4 Analyzed $\mathrm{Pb}$ content in the condensed water showing the effect of the container material on the hydrothermal treatment of glass B

\begin{tabular}{lll}
\hline Condition & Container material & $\begin{array}{l}\mathrm{Pb} \\
\text { content / } \\
\mathrm{mg} \mathrm{L}^{-1}\end{array}$ \\
\hline S. Water & Iron & 24.5 \\
& Copper & 4.8 \\
\hline
\end{tabular}

\subsection{Reduced lead metal extraction from waste funnel glass by the hydrothermal treatment}

On the basis of the above results for the synthesized $\mathrm{PbO}$-containing borosilicate glass, extraction of lead as a metallic phase from waste funnel glass $A$ was attempted with a subcritical steam hydrothermal treatment at $613 \mathrm{~K}$ with iron as the container material. Although phase separation and selective dissolution of the $\mathrm{B}_{2} \mathrm{O}_{3}$-rich decomposed glass phase by the subcritical steam did not occur for the $\mathrm{B}_{2} \mathrm{O}_{3}$-free waste funnel glass, lead reduction and precipitation proceeded through leaching of $\mathrm{Pb}^{2+}$ from the glass.

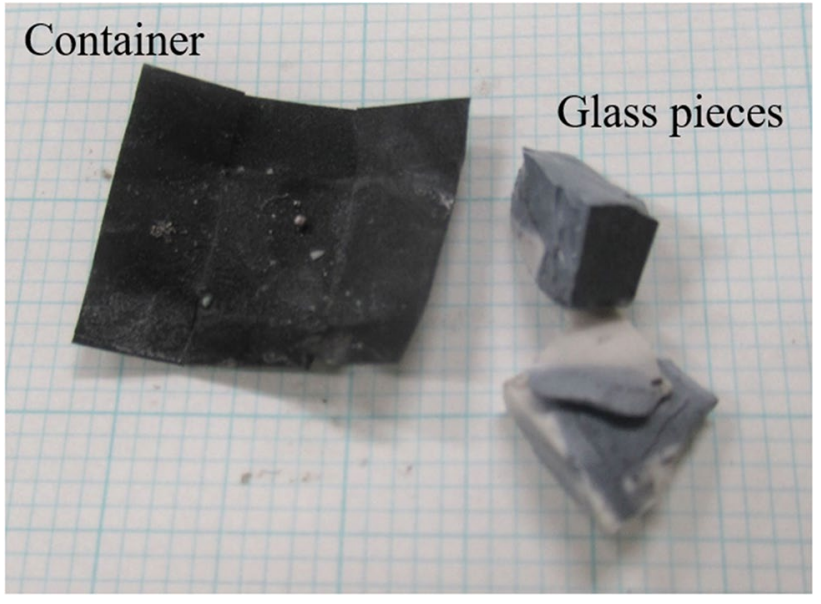

Fig. 12 Appearance of waste funnel glass $\mathrm{A}$ and iron container after subcritical steam hydrothermal treatment at $613 \mathrm{~K}$ for $48 \mathrm{~h}$

Figure 12 shows the appearances of the glass sample $A$ and the iron container after the hydrothermal treatment. The glass samples became opaque and partially black; however, no expansion related to phase separation occur. The iron container lost its metallic luster and 
turned black, as observed when hydrothermally treated with the PbO-containing borosilicate glass $\mathrm{B}$. Figure 13 shows the XRD patterns of the resulting glass $A$ and the container (inner and outer surface). In the resulting glass, a $\mathrm{KAISi}_{3} \mathrm{O}_{8}$ crystalline phase was detected, as reported by Akai et al. [18], as well as metallic lead. In both the inner and outer surfaces of the container, metallic lead and iron oxide (magnetite, $\mathrm{Fe}_{3} \mathrm{O}_{4}$ ) phases were detected.

Figure 14 shows micrographs and EDX mapping results of outer surface of the iron container after the hydrothermal treatment with waste funnel glass under subcritical steam. Many droplets of several or several tens micrometer in diameters were observed, which were identified as metallic lead. In addition, several rodlike structures corresponding to $\mathrm{KAISi}_{3} \mathrm{O}_{8}$ crystals and iron oxide on the matrix were also observed.

Thus, metallic lead was successfully obtained by the hydrothermal treatment of waste funnel glass in an iron container at $613 \mathrm{~K}$.

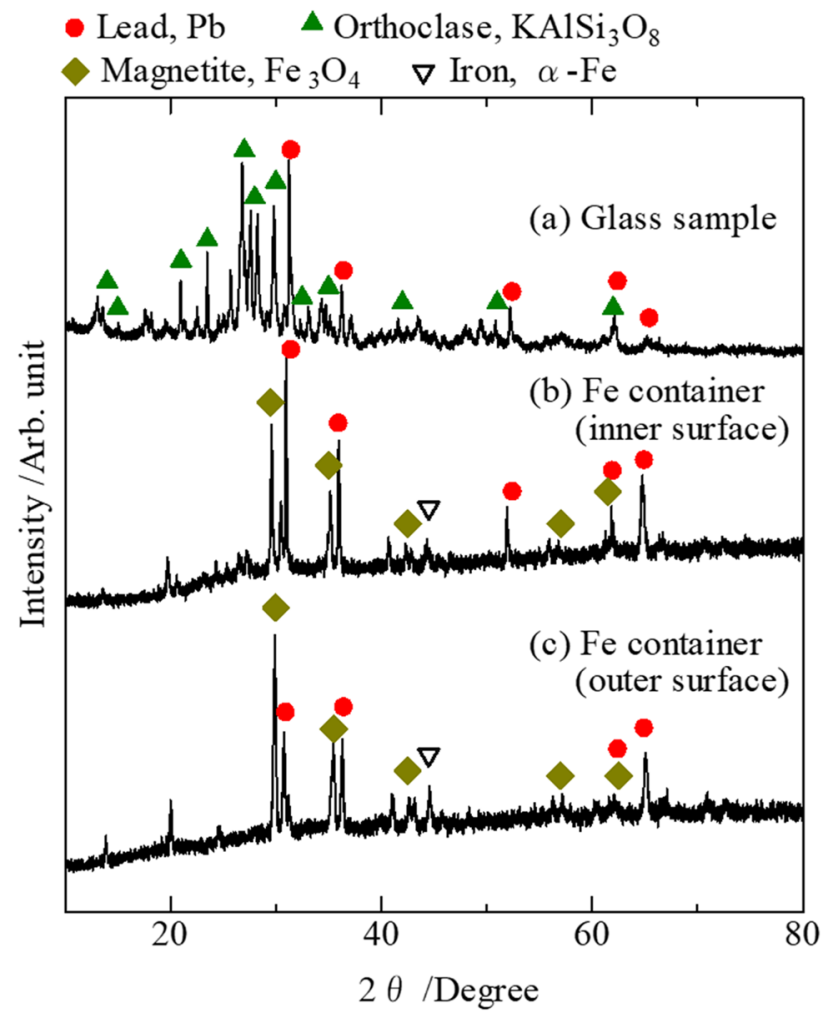

Fig. 13 X-ray diffraction patterns of a glass sample A, $\mathbf{b}$ inner surface of iron container, c outer surface of iron container, after subcritical steam hydrothermal treatment at $613 \mathrm{~K}$ for $48 \mathrm{~h}$

\section{Discussion}

\subsection{Mechanism of metallic lead precipitation under hydrothermal environment}

The above experimental results show that both subcritical steam or water environments and a reductant are essential to extract lead as metallic phase from silicate glass during hydrothermal treatments. The results of chemical analysis of the condensed water (see Tables 3,4 ) indicate that the subcritical steam or water leaches $\mathrm{Pb}^{2+}$ out of the glass. In addition, the result that metallic lead precipitates were observed when the glass sample was hydrothermally treated with stainless steel or iron container probably indicates that metallic iron as the major component of the container could have acted as a reductant to react with the $\mathrm{Pb}^{2+}$ ion in the subcritical water or steam and made it deposited as a metallic lead after formation of iron oxide phase $\left(\mathrm{Fe}_{3} \mathrm{O}_{4(\mathrm{~s})}\right)$. This redox reaction is possible because metallic iron was more likely to be oxidized than metallic lead. In particular, the spherical shape of the reduced metallic lead deposits (see Fig. 10) indicates that they precipitated in the liquid state, so the precipitation should have occurred at a higher temperature than melting point of metallic lead $(600 \mathrm{~K})$, which is close to the holding temperature during the hydrothermal treatment.

The detail of the suggested mechanism of the metallic lead precipitation is explained as below. In the case where $\mathrm{PbO}$-containing silicate glass is hydrothermally treated under subcritical water or steam with an iron container, leaching of $\mathrm{Pb}^{2+}$ ion from the glass occurs by the following chemical reaction (2):

$\mathrm{PbO}_{\text {(in silicate glass) }}+\mathrm{H}^{+} \rightarrow \mathrm{Pb}_{\text {(in subcritical water) }}^{2+}+\mathrm{OH}^{-}$

The leached $\mathrm{Pb}^{2+}$ ion diffuses in the subcritical water or dispersed in the steam. When the $\mathrm{Pb}^{2+}$ ion reaches the surface of the iron container, the redox reaction (3) occurs between $\mathrm{Pb}^{2+}$ ion in the subcritical water or steam and metallic iron in the container:

$4 \mathrm{~Pb}_{\text {(in subcritical water) }}^{2+}+4 \mathrm{OH}^{-}+3 \mathrm{Fe}_{(\mathrm{s})} \rightarrow 4 \mathrm{~Pb}_{(\mathrm{l})}+\mathrm{Fe}_{3} \mathrm{O}_{4(\mathrm{~s})}+4 \mathrm{H}^{+}$

Because reaction (3) generates protons $\left(\mathrm{H}^{+}\right)$, the leaching reaction (2) is promoted to dissolve more $\mathrm{Pb}$ element into the subcritical water as $\mathrm{Pb}^{2+}$ ion.

Here, the decomposition of $\mathrm{H}_{2} \mathrm{O}$ into $\mathrm{H}^{+}$and $\mathrm{OH}^{-}$ions is as follows:

$\mathrm{H}_{2} \mathrm{O}_{(I)} \rightleftharpoons \mathrm{H}^{+}+\mathrm{OH}^{-}$

By combining Eqs. (2), (3), and (4) to offset $\mathrm{Pb}^{2+}$ in subcritical water, the following total reaction is derived as 

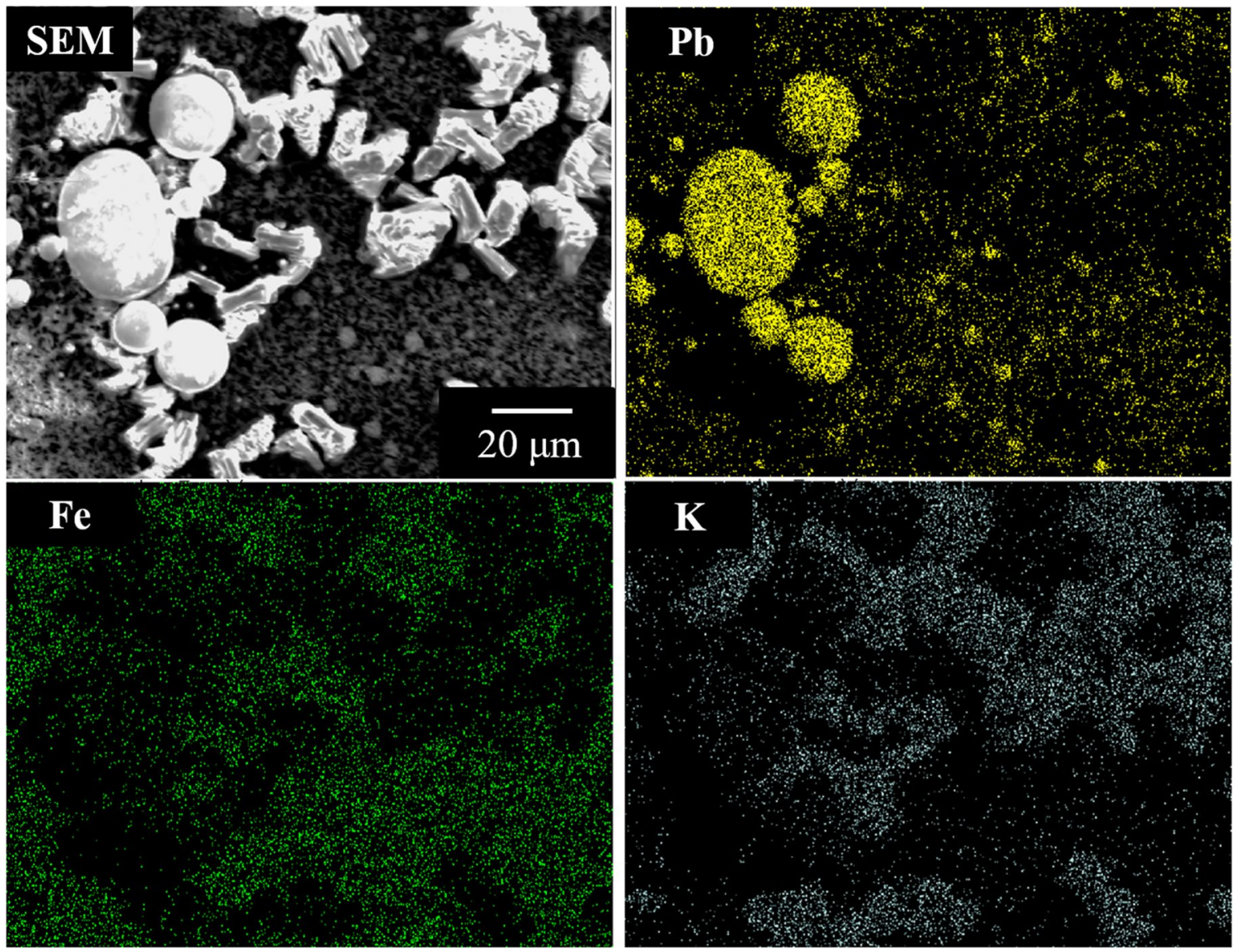

Fig. 14 Surface micrograph and EDX mapping results of iron container subjected to subcritical steam hydrothermal treatment with glass A at $613 \mathrm{~K}$ for $48 \mathrm{~h}$

(5), which reduces to a redox reaction between $\mathrm{PbO}$ in the glass and metallic iron:

$4 \mathrm{PbO}_{\text {(in silicate glass) }}+3 \mathrm{Fe}_{(\mathrm{s})} \rightarrow 4 \mathrm{~Pb}_{(\mathrm{l})}+\mathrm{Fe}_{3} \mathrm{O}_{4(\mathrm{~s})}$

Because iron is more likely to be oxidized than lead, the overall reaction (5) proceeds in the forward direction simultaneously generating metallic lead and iron oxide phases. However, the directions of the individual reactions (2) and (3) depend on the $\mathrm{pH}$ condition in the subcritical water environment.

A thermodynamic analysis was performed with the FactSage 7.3 thermodynamic computation software and the latest thermodynamic databases of pure substances and aqueous solution [19], to predict the phase equilibrium in the $\mathrm{Pb}-\mathrm{Fe}-\mathrm{H}_{2} \mathrm{O}$ system at $613 \mathrm{~K}$. The calculated phase diagram is shown in Fig. 15, where all available species of the pure metal, stoichiometric oxide, and aqueous ions were taken into account. This result indicates that, $\mathrm{Pb}^{2+}$ ion in the subcritical water is stable at the $\mathrm{pH}$-range lower than 6 and at higher electrochemical potentials than $-0.56 \mathrm{~V}$, whereas metallic lead $\left(\mathrm{Pb}_{(\mathrm{l})}\right)$ is stable the $\mathrm{pH}$-range lower than 11 and at lower electrochemical potentials than the above. In contrast, iron oxide phase (either $\mathrm{Fe}_{3} \mathrm{O}_{4(\mathrm{~s})}$ or $\mathrm{Fe}_{2} \mathrm{O}_{3(\mathrm{~s})}$ ) is stable in a wide range of $\mathrm{pH}$ and electrochemical potential. Consequently, coexistence of metallic lead and magnetite $\left(\mathrm{Fe}_{3} \mathrm{O}_{4(\mathrm{~s})}\right)$ is possible in the $\mathrm{pH}$-range of 5-11 and at lower electrochemical potentials than $-0.56 \mathrm{~V}$ (Area in Fig. 15 surrounded by red solid line). Therefore, we suggest that the reaction (2) is less likely to proceed in the forward direction in the above $\mathrm{pH}$-range. However, the reaction (3) should occur in the forward direction at a high $\mathrm{pH}$ as long as $\mathrm{Pb}^{2+}$ ion is contacted with metallic iron as the container material.

Notably, reduction and precipitation of metallic lead could occur in the absence of hydrogen gas, because the E-pH condition for coexistence of $\mathrm{Pb}_{(\mathrm{ll})}$ and $\mathrm{Fe}_{3} \mathrm{O}_{4(\mathrm{~s})}$ in Fig. 15 overlaps the phase boundary of hydrogen gas formation.

To verify the occurrence of the reaction (3) at a high $\mathrm{pH}$ condition, the additional experiments of hydrothermal treatment were conducted. The following two conditions 
Fig. 15 Phase diagram of $\mathrm{Pb}-\mathrm{Fe}-\mathrm{H}_{2} \mathrm{O}$ system at $613 \mathrm{~K}$ as functions of $\mathrm{pH}$ and electrochemical potential (E), predicted by thermodynamic analysis with the use of FactSage 7.3 software

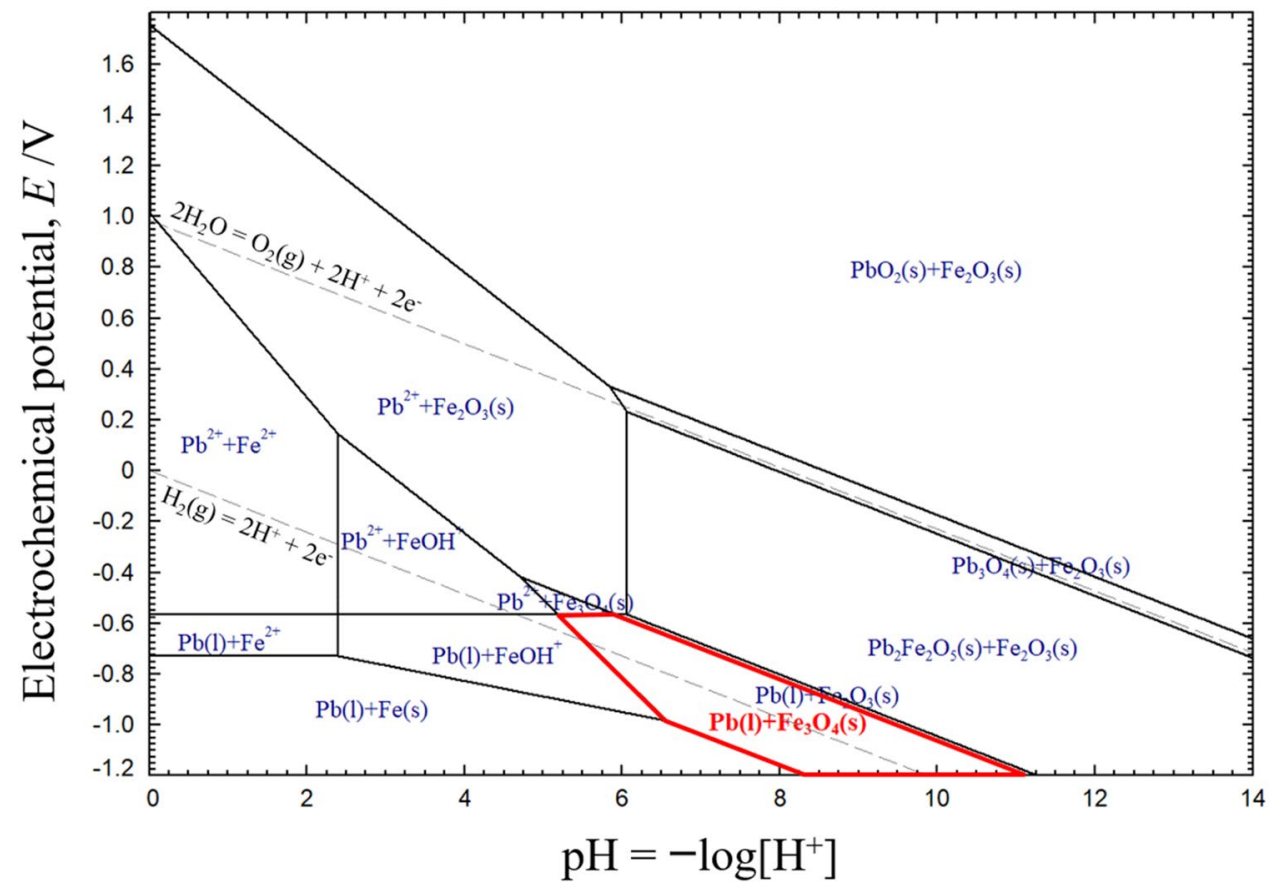

were selected: (a) aqueous solution containing $100 \mathrm{mg} \mathrm{L}^{-1}$ of elemental $\mathrm{Pb}$ (initial $\mathrm{pH}$ was adjusted as 3 ) and iron container, and (b) the above aqueous solution, iron container and a PbO-free sodium borosilicate glass (27 $\mathrm{Na}_{2} \mathrm{O}-10$ $\mathrm{B}_{2} \mathrm{O}_{3}-63$ mass $\% \mathrm{SiO}_{2}$ ) were sealed in the autoclave and held at $613 \mathrm{~K}$ for $48 \mathrm{~h}$ to make subcritical water hydrothermal condition. In the case (b), the sodium borosilicate glass was provided to increase $\mathrm{pH}$ in the subcritical water by leaching reaction of alkaline component. We measured $\mathrm{pH}$ of the aqueous solution in the case (b) after the hydrothermal treatment, and confirmed that it achieved to around 10. The appearances of the containers after the hydrothermal treatment are shown in Fig. 16A. In the case (a), the surface of the container was brown-colored homogeneously. In the case (b), the container was blackcolored and many small droplets were deposited. Almost all of glass sample was lost by the leaching reaction of the components into subcritical water. The XRD patterns of the containers after the hydrothermal treatment are shown in Fig. 16B, where only iron oxide phases were detected in the case (a) while metallic lead and magnetite $\left(\mathrm{Fe}_{3} \mathrm{O}_{4(\mathrm{~s})}\right)$ were identified in the case (b). The above result clearly indicates that $\mathrm{Pb}^{2+}$ ion in the subcritical water reacted with iron in the container to be precipitated as metallic lead by the redox reaction (3), and that this reaction occurs only in the high $\mathrm{pH}$ condition where coexistence of $\mathrm{Pb}_{(\mathrm{I})}$ and $\mathrm{Fe}_{3} \mathrm{O}_{4(\mathrm{~s})}$ is thermodynamically stable.

In some cases, metallic lead was deposited on the surface of the glass sample, as shown in Figs. 5, 6. Although elemental Fe was not detected in the condensed water after hydrothermal treatment, it is possible that elemental
Fe partially leached from the container into the subcritical water or steam and migrated as $\mathrm{Fe}^{2+}$ to react with $\mathrm{Pb}^{2+}$ leached from the glass to form the metallic lead precipitate by the following reaction:

$2 \mathrm{Fe}^{2+}+\mathrm{Pb}^{2+} \rightarrow \mathrm{Pb}_{(l)}+2 \mathrm{Fe}^{3+}$

Thus, reduction of $\mathrm{Pb}^{2+}$ ion to metallic lead by $\mathrm{Fe}^{2+}$ ions in the subcritical water was thermodynamically favorable. The above $\mathrm{Fe}^{2+}$ and $\mathrm{Fe}^{3+}$ ions may have reacted with subcritical water or steam and precipitated as $\mathrm{Fe}_{3} \mathrm{O}_{4(\mathrm{~s})}$, or iron hydroxide with amorphous state so that it could not be recognized by XRD analysis.

However, in this study, the actual mechanism of metallic lead precipitation by the hydrothermal treatment of the $\mathrm{PbO}$-containing glass could not be completely clarified. Further experiments, where $\mathrm{pH}$ of the subcritical water and electrochemical potential of the container are controlled during the hydrothermal treatment, are necessary to verify the mechanism suggested in the above.

\subsection{Lead recovery rate from $\mathrm{PbO}$-containing glass by hydrothermal treatment}

Table 5 shows a representative value of the analyzed $\mathrm{Pb}$ contents in the glass before and after the hydrothermal treatment with subcritical water at $613 \mathrm{~K}$. Although many metallic lead deposits were observed, the elemental $\mathrm{Pb}$ content of the glass after the hydrothermal treatment was comparable to that of the as-synthesized glass and the lead recovery rate was estimated to be low. Although the condensed 
[A] Sample appearance (inner surface)

(a) Fe container

$+\mathrm{Pb}$ aqueous solution $(\mathrm{pH}=3)$

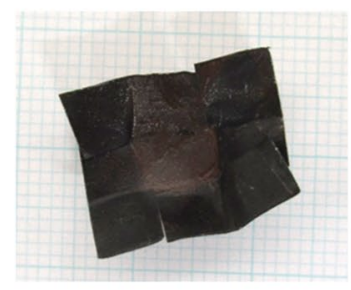

(b) Fe container

$+\mathrm{Pb}$ aqueous solution $(\mathrm{pH}=3)$

+ Sodium borosilicate glass

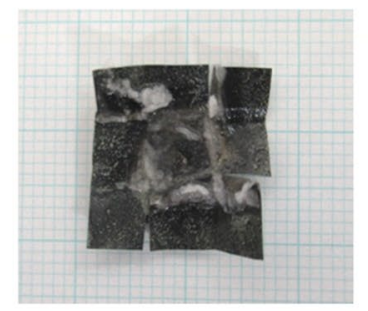

[B] X-ray diffraction patterns

- Lead, $\mathrm{Pb} \quad \nabla$ Iron, $\alpha$-Fe $\quad \nabla$ Quartz, $\mathrm{SiO}_{2}$ Magnetite, $\mathrm{Fe}_{3} \mathrm{O}_{4}$ 回 Hematite, $\mathrm{Fe}_{2} \mathrm{O}_{3}$

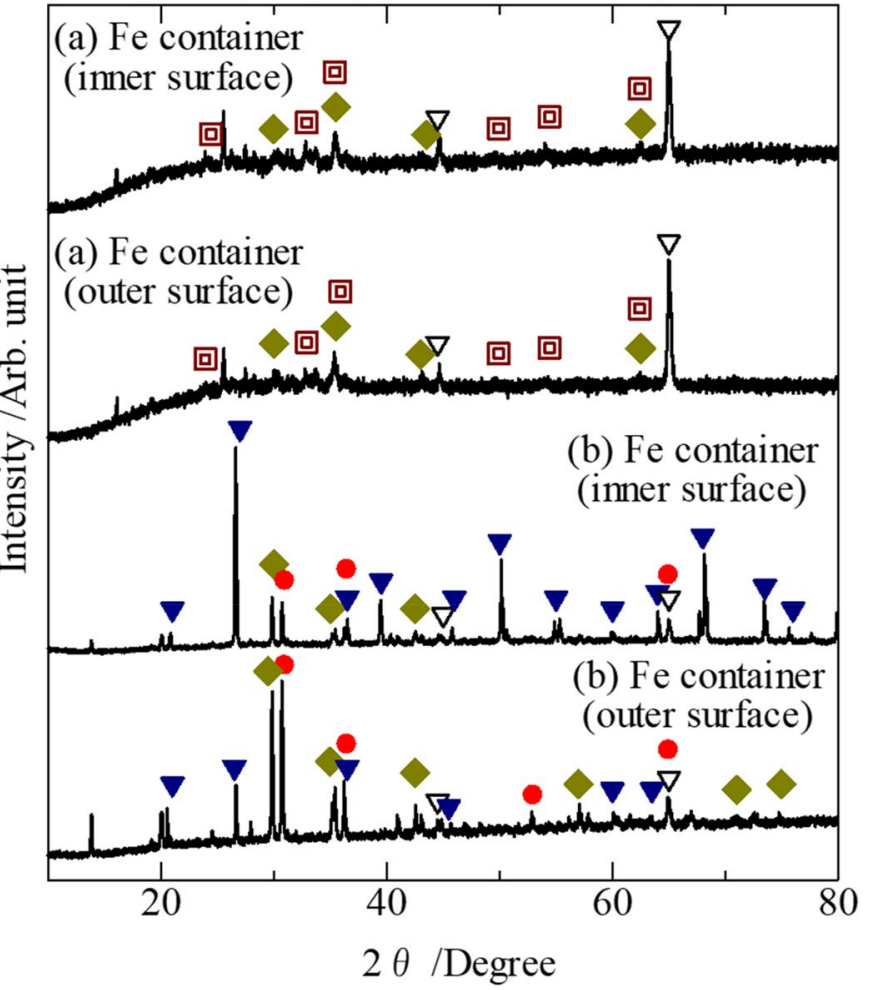

Fig. 16 A Appearance and B X-ray diffraction patterns of iron container subjected to subcritical water hydrothermal treatment with Pbcontaining aqueous solution at $613 \mathrm{~K}$ for $48 \mathrm{~h}$

Table 5 Range of $\mathrm{Pb}$ contents in glass $\mathrm{B}$ analyzed before and after hydrothermal treatment

\begin{tabular}{ll}
\hline Condition & $\begin{array}{l}\text { Pb content in } \\
\text { glass } / \text { mass } \%\end{array}$ \\
\hline $\begin{array}{l}\text { As synthesized } \\
\text { After hydrothermal treatment (in subcritical water, } \\
\text { with iron container) }\end{array}$ & $15.9-17.0$ \\
$14.8-18.3$
\end{tabular}

water contained a certain amount of elemental $\mathrm{Pb}$ leached as $\mathrm{Pb}^{2+}$ ion (see Tables 3, 4), which exceeded the solubility limit of elemental $\mathrm{Pb}$ when pure solid $\mathrm{PbO}$ reacts with water at room temperature $\left(17 \mathrm{mg} \mathrm{L}^{-1}\right)$ [20], the amount of $\mathrm{PbO}$ in the glass reacted with water was still low, likely because of the high $\mathrm{pH}$. Thus, the initial $\mathrm{pH}$ of the subcritical water should be lowered to increase the elemental $\mathrm{Pb}$ dissolution rate from the silicate glass by Eq. (2). In addition, the metallic lead precipitation may be suppressed when the surface of the iron container becomes covered by the generated $\mathrm{Fe}_{3} \mathrm{O}_{4}$. In this case, removal of the iron oxide film from the container is required to promote metallic lead precipitation by Eq. (3).
The improvements proposed above should contribute to achieve a high lead recovery rate.

However, it would be still difficult to completely remove all amount of elemental $\mathrm{Pb}$ from the glass by a single hydrothermal treatment. To reduce environmental pollution risk by remaining $\mathrm{Pb}$ element in the glass, the repetition of the hydrothermal treatment with a new reductant material would be necessary.

Finally, a possible method for separation of metallic lead from the container is proposed here. Because many of the metallic lead deposits on the iron container were spherical (see Fig. 10), the deposits could have been removed from the surface of the container by an ultrasonic vibration. However, for high efficiency of metallic lead separation, it would be necessary to enhance the size of the deposits. This could be achieved by the improvement of hydrothermal process as mentioned above. 


\section{Conclusions}

In this study, lead was directly extracted as a metallic phase from $\mathrm{PbO}$-containing waste silicate glass by a hydrothermal treatment at $613 \mathrm{~K}$ under subcritical water or steam condition. The roles of subcritical water environment and the container materials in promoting metallic lead deposition were experimentally investigated. Our conclusions are summarized as follows:

- When synthesized PbO-containing borosilicate glass and a stainless-steel container were provided for hydrothermal treatment, metallic lead was spontaneously deposited on the surface of the glass. In addition, the analytical results of the condensed water indicated that the subcritical water environment likely promoted leaching of $\mathrm{Pb}^{2+}$ from the glass. In contrast, no obvious changes occurred in the glass following a heat treatment in dry air.

- Precipitation of metallic lead occurred when the container made of stainless-steel or iron and PbO-containing glass are under the subcritical water or steam conditions at $613 \mathrm{~K}$, whereas the precipitation did not occur when a copper container was placed with the glass in the above hydrothermal treatments. In the case where $\mathrm{PbO}$-containing glass and an iron container were taken to the subcritical water hydrothermal treatment, the metallic lead particles were mainly deposited on the surface of the iron container and iron oxide $\left(\mathrm{Fe}_{3} \mathrm{O}_{4}\right)$ was also formed.

- By applying the hydrothermal treatment to a waste funnel glass with an iron container, metallic lead precipitates were successfully obtained.

- From the above all experiments, the redox reaction between $\mathrm{Pb}^{2+}$ ion in the subcritical water and metallic iron in the container material was suggested as a possible mechanism to precipitate metallic lead particles. In this case, metallic iron was likely to act as a reductant material because metallic iron is more easily oxidized than metallic lead.

The above hydrothermal reduction could be applied as a low energy, simple, and eco-friendly method to extract lead from waste oxide glass and directly precipitate as a metallic phase with the provision of a suitable reductant material in the subcritical water environment.

Acknowledgement We thank Panasonic Eco Technology Center Co. Ltd., (Hyogo, Japan) for supply of waste funnel glass sample. We thank Ms. Yukari Miki (graduate student, Osaka University, Japan) for cooperation to preliminary experiments of hydrothermal treatment of $\mathrm{PbO}$-containing borosilicate glass. Finally, we thank Andrew Jackson, Ph.D., from Edanz Group (https://en-author-services.edanz group.com/ac) for editing a draft of this manuscript.

\section{Compliance with ethical standards}

Conflicts of interest The authors declare that there are no conflicts of interest in this manuscript.

Open Access This article is licensed under a Creative Commons Attribution 4.0 International License, which permits use, sharing, adaptation, distribution and reproduction in any medium or format, as long as you give appropriate credit to the original author(s) and the source, provide a link to the Creative Commons licence, and indicate if changes were made. The images or other third party material in this article are included in the article's Creative Commons licence, unless indicated otherwise in a credit line to the material. If material is not included in the article's Creative Commons licence and your intended use is not permitted by statutory regulation or exceeds the permitted use, you will need to obtain permission directly from the copyright holder. To view a copy of this licence, visit http://creativecommons .org/licenses/by/4.0/.

\section{References}

1. Méar F, Yot P, Cambon M, Ribes M (2006) The characterization of waste cathode-ray tube glass. Waste Manag 26(12):1468-1476

2. Ishida I (2001) Recycling of glass from the end of life TV sets. NEW GLASS 16:20-26 ((In Japanese))

3. Industry Council for Electronic Equipment Recycling (ICER) New approach to Cathode Ray Tube (CRT) recycling (2003) http:// www.glass-ts.com/userfiles/files/2003-08\%20New\%20App roach $\% 20$ to $\% 20$ Cathode\%20Ray $\% 20$ Tube $\% 20$ (CRT)\%20Rec ycling.pdf

4. Industry Council for Recycling and Disposal of Cathode Ray Tube (CRT) Glass Cullet, Ministry of Environment, Government of Japan (2011). https://www.env.go.jp/recycle/kaden/conf/ crt_grasscullet/torimatome_pdf/full.pdf (In Japanese)

5. Inano H, Tomita K, Tada T, Hiroyoshi N (2018) Lead generation and separation mechanisms from lead silicate glass by reduction-melting. J Ceram Soc Jpn 126(8):595-601

6. Chen D, Masui H, Miyoshi H, Akai T, Yazawa T (2006) Extraction of heavy metal ions from waste colored glass through phase separation. Waste Manag 26(12):1017-1023

7. Suzuki M, Tanaka T (2008) Materials design for the fabrication of porous glass using phase separation in multi-component borosilicate glass. ISIJ Int 48(11):1524-1532

8. Suzuki M, Tanaka T (2010) Distribution and coordination state of titanium oxides in microstructures formed by spinodal decomposition in multicomponent borosilicate glass. ISIJ Int 50(4):509-514

9. Sigoli FA, Kawano Y, Davolos MR, Jafelicii M Jr (2001) Phase separation in pyrex glass by hydrothermal treatment: evidence from micro-Raman spectroscopy. J Non-cryst Solids 284:49-54

10. Nakamoto M, Lee J, Tanaka T, Ikeda J, Itagaki S (2005) Use of slag containing water as a lubricant in high straining rolling for ultra-grained steels. ISIJ Int 45(11):1567-1571

11. Luo J, Huynh H, Pantano CG, Kim SH (2016) Hydrothermal reactions of soda lime silica glass-revealing subsurface damage and alteration of mechanical properties and chemical structure of glass surfaces. J Non-cryst Solids 452:93-101

12. Suzuki M, Tanaka T, Yamasaki N (2014) Use of hydrothermal reactions for slag/glass recycling to fabricate porous materials. Curr Opin Chem Eng 3:7-12 
13. Arita T, Hitaka H, Minami K, Naka T, Adschiri T (2011) Synthesis of iron nanoparticle: challenge to determine the limit of hydrogen reduction in supercritical water. J Supercrit Fluids 57(2):183-189

14. Seong G, Takami S, Arita T, Minami K, Hojo D, Yavari AR, Adschiri $T$ (2011) Supercritical hydrothermal synthesis of metallic cobalt nanoparticles and its thermodynamic analysis. J Supercrit Fluids 60(1):113-120

15. Seong G, Adschiri T (2014) The reductive supercritical hydrothermal process, a novel synthesis method for cobalt nanoparticles: synthesis and investigation on the reaction mechanism. Dalton Trans 43:10778-10786

16. Jin Y, Korablova IR,Kato H, Yamasaki N (2004) Studies on masstransformation in water vapor near critical point. In: Proc. 14th int conf properties of water and steam, Kyoto, Japan, pp 274-281

17. Wagner W, Saul A, Pruss A (1994) International equations for the pressure along the melting and along the sublimation curve of ordinary water substance. J Phys Chem Ref Data 23(3):515-527
18. Miyoshi H, Chen D, Akai T (2004) A novel process utilizing subcritical water to remove lead from wasted lead silicate glass. Chem Lett 33(8):956-957

19. FactSage. http://www.factsage.com/. Assessed 18 Sep 2020

20. IARC (1980) Monographs on the evaluation of the carcinogenic risk of chemicals to humans. World Health Organization, International Agency for Research on Cancer, Geneva, p. V23: 327, 1972-PRESENT. http://monographs.iarc.fr/ENG/Classification/ index.php

Publisher's Note Springer Nature remains neutral with regard to jurisdictional claims in published maps and institutional affiliations. 